\title{
Identificação, Prevenção e Tratamento da Síndrome Mão-Pé Induzida por Quimioterapia: Revisão Sistemática
}

https://doi.org/10.32635/2176-9745.RBC.2019v65n4.363

\author{
Identification, Prevention and Treatment of Hand-Foot Syndrome Induced by Chemotherapy: Systematic Review \\ Identificación, Prevención y Tratamiento de la Enfermedad Mental por Quimioterapia: Revisión Sistemática
}

Paulina Patente Pereira'; Reginaldo dos Santos Pedroso²; Maria Ângela Ribeiro ${ }^{3}$

Resumo

Introdução: A síndrome mão-pé é uma reação adversa experimentada por vários pacientes em tratamento para o câncer e fator preditor de morbidade e mortalidade. Objetivo: Avaliar as evidências científicas relacionadas à identificação, prevenção e tratamento da síndrome mão-pé induzida por agentes quimioterápicos, identificar os principais sinais e sintomas que possibilitam o reconhecimento da síndrome e, ainda, discutir a ocorrência de onicomicoses no contexto da síndrome mão-pé. Método: Trata-se de uma revisão sistemática na MEDLINE/PubMed, Biblioteca Virtual da Saúde e Scopus, incluindo literatura cinzenta e busca manual. Os 29 estudos incluídos na revisão foram analisados e classificados segundo a hierarquia dos níveis de evidência Grading of Recommendations Assessment, Development and Evaluations (GRADE) e a confiabilidade entre os examinadores (coeficiente Kappa) foi calculada. Resultados: Foram identificados estudos que demonstraram eficácia na prevenção da síndrome mão-pé com o uso da crioterapia e hidroterapia. Evidenciaram-se resultados satisfatórios com o uso do creme de ureia na prevenção e tratamento, e o uso de piridoxina não apresentou resultados conclusivos. Foram encontrados mecanismos para identificação da síndrome e para classificação dos agentes indutores. O grupo dos taxanos predominou entre os medicamentos indutores da síndrome mão-pé. Conclusão: Existem evidências consistentes, porém não contemplam todos os fármacos indutores da síndrome e não exploram outras manifestações relacionadas às onicólises e onicomicoses. O estudo apresentou resultados que poderão auxiliar os prescritores na identificação da síndrome mão-pé, além de alternativas para prevençâo e tratamento. Contudo, vale destacar a necessidade de pesquisas futuras para elucidar a etiologia e protocolos de tratamento.

Palavras-chave: Síndrome Mão-Pé/tratamento farmacológico; Antineoplásicos; Onicomicose; Onicólise; Taxoides.

\begin{abstract}
Introduction: Hand-foot syndrome is an adverse reaction experienced by many cancer patients and a predictor of morbidity and mortality. Objective: To evaluate the scientific evidence related to the identification, prevention and treatment of chemotherapeutic-induced hand-foot syndrome, to identify the main signs and symptoms that enable the recognition of the syndrome, and to discuss the occurrence of onychomycosis in the context of the hand-foot syndrome. Method: This is a systematic review at MEDLINE/PubMed, Virtual Health Library and Scopus, including gray literature and manual search. The 29 studies included in the review were analyzed and graded according to the hierarchy of evidence levels Grading of Recommendations Assessment, Development and Evaluations (GRADE) and reliability among examiners (Kappa coefficient) was calculated. Results: It were identified studies that demonstrated efficacy in preventing hand-foot syndrome using cryotherapy and hydrotherapy. Satisfactory results were evidenced with the use of urea cream for prevention and treatment, and the use of pyridoxine showed inconclusive results. Mechanisms for identification of the syndrome and classification of inducing agents were found. The taxane group predominated among hand-foot syndrome inducing drugs. Conclusion: There are consistent evidences but do not include all drugs inducing the syndrome and do not explore other manifestations related to onycholysis and onychomycosis. The study presented results that may help prescribers to identify hand-foot syndrome, as well as alternatives for prevention and treatment. However, it is worth highlighting the need for future studies to elucidate the etiology and treatment protocols.

Key words: Hand-Foot Syndrome/drug therapy; Antineoplastic Agents; Onychomycosis; Onycholysis; Taxoids.
\end{abstract}

Resumen

Introducción: El síndrome de pies y manos es una reacción adversa experimentada por muchos pacientes con cáncer y un predictor de morbilidad y mortalidad. Objetivo: Evaluar la evidencia científica relacionada con la identificación, prevención y tratamiento del síndrome de pies y manos inducido por quimioterapia, identificar los principales signos y síntomas que permiten el reconocimiento del síndrome y analizar la aparición de onicomicosis en el contexto del síndrome mano-pie. Método: Esta es una revisión sistemática en MEDLINE/PubMed, Virtual Health Library y Scopus, que incluye literatura gris y búsqueda manual. Los 29 estudios incluidos en la revisión se analizaron y clasificaron de acuerdo con la jerarquía de los niveles de evidencia Grading of Recommendations Assessment, Development and Evaluations (GRADE). Resultados: Identificamos estudios que demostraron eficacia en la prevención del síndrome mano-pie usando crioterapia e hidroterapia. También mostraron resultados satisfactorios con el uso de crema de urea en la prevención y el tratamiento, y el uso de piridoxina no mostró resultados concluyentes. Se encontraron mecanismos para la identificación del síndrome y la clasificación de los agentes inductores. El grupo de taxanos predominó entre los fármacos inductores del síndrome mano-pie. Conclusión: Existe evidencia consistente pero no incluye todas las drogas que inducen el síndrome y no explora otras manifestaciones relacionadas con la onicólisis y la onicomicosis. El estudio presentó resultados que pueden ayudar a los prescriptores a identificar el síndrome de manos y pies, así como alternativas para la prevención y el tratamiento. Sin embargo, vale la pena destacar la necesidad de futuras investigaciones para dilucidar la etiología y los protocolos de tratamiento.

Palabras clave: Síndrome Mano-Pie/tratamiento farmacológico; Antineoplásicos; Onicomicosis; Onicólisis; Taxoides.

\footnotetext{
${ }^{1}$ Universidade Federal de Uberlândia. Uberlândia (MG), Brasil. Orcid iD: https://orcid.org/0000.0002.3588.9175 ${ }^{2}$ Universidade Federal de Uberlândia. Uberlândia (MG), Brasil. Orcid iD: https://orcid.org/0000.0003.3010.5754 ${ }^{3}$ Universidade Federal de Uberlândia. Uberlândia (MG), Brasil. Orcid iD: https://orcid.org/0000.0002.1522.4299 Endereço para correspondência: Maria Ângela Ribeiro. Av. Floriano Peixoto, 5322 - Bloco 12 - Apto. 3 - Alto Umuarama. Uberlândia (MG), Brasil. CEP $38405-373$. E-mail: ribeiromaribeiro@yahoo.com.br
} 


\section{INTRODUÇÃO}

O câncer é uma doença em ascensão ${ }^{1}$ e com necessidade de cuidado integral ao paciente ${ }^{2,3}$. Isso exige tanto o aumento em investimento nacional na pesquisa, como a aplicação do conhecimento na prevenção, controle e manejo da doença em todos os seus segmentos ${ }^{3}$.

No Brasil, o Instituto Nacional de Câncer José Alencar Gomes da Silva (INCA) estimou um aumento de $600 \mathrm{mil}$ casos novos para cada ano do biênio 2018-2019, para todos os tipos da doença, exceto pele não melanoma ${ }^{4}$. Por outro lado, a taxa de sobrevivência aumentou, com uma média de $92 \%$ para próstata e $85 \%$ para a neoplasia da mama ${ }^{4}$. Esse aumento tem ocorrido em razão do diagnóstico precoce, aliado à consolidaçáo de tratamentos neoadjuvantes e adjuvantes ${ }^{4}$. No entanto, as inúmeras reaçôes adversas desses tratamentos, como fadiga, sarcopenia, osteopenia, osteoporose, disfunção cardiovascular, excesso de peso, imunossupressão, distúrbios do sono e síndrome mão-pé, contribuem para piorar o estado de saúde e a qualidade de vida dos pacientes 5 .

A síndrome mão-pé é também conhecida como eritema palmoplantar, eritema acral ou reação de Burgdorf. É uma reação adversa experimentada por vários pacientes em tratamento com quimioterapia ${ }^{6} \mathrm{com}$ um potencial de toxicidade cutânea limitante ao uso da dose efetiva para o tratamento.

A incidência dessa síndrome varia de $20 \%$ a $60 \%$ entre os pacientes tratados, de acordo com o fármaco em uso. Entre os fármacos indutores, estâo os citostáticos, citotóxicos e/ou imunoterápicos como: doxorrubicina lipossomal peguilada, doxorrubicina, capecitabina, mitotano, ciclofosfamida, 5-fluorouracil, citarabina, docetaxel, paclitaxel, sorafenibe, sunitinibe e gefitinibe ${ }^{5,6}$. No entanto, a síndrome mão-pé é um tema ainda bastante controverso na oncologia ${ }^{6}$.

Esta foi documentada pela primeira vez em 1974 por Zuehlke ${ }^{7}$, destacando a sua manifestação após o uso de mitotano ${ }^{7}$. Apresenta os seguintes sintomas: prurido, dor, edema e eritema acral nas palmas das máos e/ou planta dos pés em graus variados, conforme descrito nos Common Terminology Criteria for Adverse Events (CTCAE), versão 5.0 de $2017^{8}$, que classificam a síndrome mão-pé em três graus, com base na severidade do acometimento. $\mathrm{O}$ grau 1 é caracterizado por alterações mínimas na pele ou dermatite indolor; o grau 2 é caracterizado por alteraçóes na pele, mas a dor não interfere em suas funçóes diárias; e o grau 3 é caracterizado por dermatite ulcerativa ou alteraçóes da pele com dor interferindo nas funçóes diárias ${ }^{8}$.

Inúmeras estratégias de prevenção e/ou tratamento têm sido empregadas na tentativa de prevenir e/ou reduzir a incidência de síndrome mão-pé, que são essenciais para a manutenção da quimioterapia e o alcance dos melhores resultados ${ }^{5,6}$.

Em revisão sistemática e metanálise ${ }^{9}$, cujo objetivo foi avaliar a eficácia clínica das estratégias de prevenção de síndrome mão-pé disponíveis na literatura, os autores avaliaram medicamentos preventivos orais e tópicos e relatam que, com o advento de novos fármacos, surgem também novos efeitos adversos, sendo assim, estudos para estratégias de prevençáo da síndrome mão-pé devem ser estimulados.

Portanto, ainda há questóes que precisam ser respondidas, entre elas, os principais sinais e sintomas apresentados pelos pacientes e que caracterizam uma síndrome mão-pé; e as estratégias de tratamentos propostos cujos mecanismos propiciam bons resultados tanto na prevençáo quanto no tratamento, assim como a relação da síndrome mão-pé com onicomicoses ${ }^{10}$.

Dessa forma, o objetivo da presente revisão foi avaliar as evidências científicas relacionadas à identificação, prevenção e tratamento da síndrome mão-pé induzida por agentes quimioterápicos, identificar os principais sinais e sintomas que possibilitam o reconhecimento da síndrome e, ainda, discutir a ocorrência de onicomicoses no contexto da síndrome mão-pé.

\section{MÉTODO}

Esta revisão sistemática foi conduzida de acordo com as Diretrizes do Relatório de Itens para Revisóes Sistemáticas e Metanálises (PRISMA) ${ }^{11}$. A pesquisa foi realizada nas bases de dados MEDLINE/PubMed, Biblioteca Virtual da Saúde (BVS) e Scopus sem restrição de data, abordando a síndrome mão-pé associada ao uso de medicamentos quimioterápicos. Cada banco de dados foi pesquisado em sua totalidade e não houve limites para idioma ou tipo de publicação. A primeira consulta às bases foi realizada nos dias 29, 30 e 31/5/2017; incluindo literatura cinzenta e busca manual em agosto/2018. O presente trabalho foi protocolado no International Prospective Register of Systematic Reviews (PROSPERO) e publicado sob n. ${ }^{\circ}$ CDR42019114757.

\section{CRITÉRIOS DE ELEGIBILIDADE, AVALIAÇÃO DA QUALIDADE E RISCOS DE VIESES}

A triagem nas bases de dados foi realizada por dois dos pesquisadores identificados pelas iniciais PPP e MAR para localizar estudos relevantes baseados em seus títulos. Quando um ou ambos os avaliadores discordaram quanto ao preenchimento dos critérios de inclusão para determinado estudo, as divergências foram resolvidas por consenso com ou sem o auxílio de um terceiro pesquisador (RSP). Em um segundo momento, seguindo as recomendaçóes da 
Cochrane Effective Practice and Organisation of Care $^{12}$, os artigos compilados na etapa inicial foram analisados, tendo sido selecionados aqueles que atendessem a todos os critérios de elegibilidade, bem como a avaliação da qualidade e o risco de vieses: 1) artigos com ensaios clínicos randomizados ou não randomizados; 2) grupos que sofreram intervenção com grupo-controle; 3) artigos que avaliaram os sintomas da síndrome mão-pé em relação às onicólises e com sugestões de tratamento; 4) estudos observacionais, inclusive série e relatos de caso que relataram sintomas e propostas de tratamento para síndrome mão-pé e onicomicoses, considerando a escassez de publicaçóes encontradas acerca do tema pesquisado (Tabela 1).

A busca ocorreu com a utilização dos parâmetros descritos nos critérios de elegibilidade, nas bases anteriormente citadas, com o auxílio de cinco estratégias de pesquisa, variando descritores MeSH/DeCs e operadores booleanos conforme descritos a seguir:
Pesquisa 1_ "hand-foot syndrome" AND "breast neoplasms" OR "breast” AND "neoplasms" OR "breast neoplasms" AND "therapy" OR "therapy" OR "treatment" OR "therapeutics" OR "therapeutics" OR "taxanes" OR "hand-foot syndrome" OR "hand-foot" AND "syndrome" OR "hand-foot syndrome" OR "hand" AND "foot" AND "syndrome" OR "hand foot syndrome" AND "breast neoplasms" OR "breast"AND "neoplasms" OR "breast neoplasms" AND "therapy" OR "therapy" OR "treatment" OR "therapeutics" OR "therapeutics" AND acral AND "erythema" OR "erythema" "hand-foot syndrome". Pesquisa 2_ "breast neoplasms" OR "breast" AND "neoplasms" OR "breast neoplasms" AND "therapy" OR "therapy" OR "treatment" OR "therapeutics" OR "therapeutics" OR "taxanes" OR "hand-foot syndrome" OR "hand-foot" AND "syndrome" OR "hand-foot syndrome" OR "hand" AND "foot" AND "syndrome" OR "hand foot syndrome" AND "quality of life" OR

Tabela 1. Descrição dos artigos selecionados

\begin{tabular}{|c|c|c|c|c|}
\hline Autor, ano & $\mathbf{N}$ & Idade média & Desenho & $\begin{array}{l}\text { Qualidade da } \\
\text { evidência }\end{array}$ \\
\hline McCarthy et al., $2014^{13}$ & 53 & 54,8 & Ensaio controlado randomizado & Alta \\
\hline Scotté et al., $2005^{14}$ & 45 & 65 & Caso-controle & Moderada \\
\hline $\begin{array}{l}\text { von Gruenigen et al., } \\
2010^{15}\end{array}$ & 34 & 64 & $\begin{array}{l}\text { Duplo-cego, randomizado, ensaio } \\
\text { clínico controlado }\end{array}$ & Alta \\
\hline Zhao et al., $2014^{16}$ & 100 & $36-78$ & $\begin{array}{c}\text { Duplo-cego, randomizado e } \\
\text { controlado }\end{array}$ & Alta \\
\hline Hofheinz et al. $2015^{17}$ & 152 & $31-88$ & Estudo clínico randomizado fase III & Alta \\
\hline Ren et al., $2015^{18}$ & 871 & $51,8-52,0$ & Estudo controlado randomizado & Alta \\
\hline Yoshimoto et al., $2010^{19}$ & 78 & $55,0-55,6$ & Estudo retrospectivo & Moderada \\
\hline Kawaguchi et al. $2011^{20}$ & 993 & Não informou & Estudo observacional retrospectivo & Moderada \\
\hline Dalenc et al., $2018^{21}$ & 70 & 70 & Estudo controlado randomizado & Alta \\
\hline Bardia et al., $2006^{22}$ & 5 & 54,2 & Série de casos & Baixa \\
\hline Farhat et al., $2008^{23}$ & 5 & 60,2 & Série de casos & Baixa \\
\hline Kara et al., $2006^{24}$ & 5 & 51,2 & Série de casos & Baixa \\
\hline Chew et al., $2009^{25}$ & 4 & 51 & Série de casos & Baixa \\
\hline Wang et al., $2016^{26}$ & 3 & $47-85$ & Série de casos & Baixa \\
\hline Corazza et al., $2014^{27}$ & 1 & 60 & Relato de caso & Baixa \\
\hline Richards et al., $2012^{28}$ & 1 & 66 & Relato de caso & Baixa \\
\hline Housholder et al., $2012^{29}$ & 1 & 63 & Relato de caso & Baixa \\
\hline Ozkol et al., $2016^{30}$ & 1 & 24 & Relato de caso & Baixa \\
\hline Sauter et al., $2007^{31}$ & 1 & 76 & Relato de caso & Baixa \\
\hline Akoglu et al., $2014^{32}$ & 1 & 52 & Relato de caso & Baixa \\
\hline Braghiroli et al., $2017^{33}$ & 1 & 73 & Relato de caso & Baixa \\
\hline Jung et al., $2015^{34}$ & 1 & 43 & Relato de caso & Baixa \\
\hline Qiao et al., $2012^{35}$ & 1 & 59 & Relato de caso & Baixa \\
\hline Katoh et al., $2004^{36}$ & 1 & 70 & Relato de caso & Baixa \\
\hline Gurumurthi et al., $2013^{37}$ & 1 & 52 & Relato de caso & Baixa \\
\hline Hoesly et al, $2011^{38}$ & 1 & 61 & Relato de caso & Baixa \\
\hline Jain et al., $2012^{39}$ & 1 & 45 & Relato de caso & Baixa \\
\hline Assi et al., $2013^{40}$ & 1 & 72 & Relato de caso & Baixa \\
\hline Simão et al. $2012^{41}$ & 1 & 37 & Relato de caso & Baixa \\
\hline
\end{tabular}


"quality" AND "life". Pesquisa 3_ "quality of life" AND "breast neoplasms" OR "breast" AND "neoplasms" OR "breast neoplasms" "hand-foot syndrome" OR "handfoot" AND "syndrome" OR "hand-foot syndrome" OR "hand" AND "foot" AND "syndrome" OR "hand foot syndrome" AND "quality of life" OR "quality" AND "life" OR "quality of life" AND "breast neoplasms" OR "breast" AND "neoplasms". Pesquisa 4_ "breast neoplasms" "onychomycosis" AND "taxanes" AND "breast neoplasms" AND "onychomycosis" AND "Handfoot syndrome" AND "mycosis" AND "taxanes" AND "breast neoplasms" AND "mycosis" AND "paclitaxel" AND "breast neoplasms" AND "mycosis" AND "Handfoot syndrome" AND "mycosis" AND "paclitaxel" AND "Hand-foot syndrome" AND "onychomycosis" AND "taxanes" AND "breast neoplasms" AND "onychomycosis". Pesquisa 5_ "Hand-foot syndrome" AND "mycosis" AND "taxanes" AND "breast neoplasms" AND "mycosis" AND "paclitaxel" AND "breast neoplasms" AND "mycosis" AND "Hand-foot syndrome" AND "mycosis" AND "paclitaxel" AND "Hand-foot syndrome".

A coleta de dados foi realizada em formulário eletrônico elaborado para esse fim, contendo as seguintes variáveis: autores do estudo e ano de publicação, país de realização do estudo, desenho do estudo, tipo de medicamento utilizado pelo paciente, número de pacientes estudados e resultados. Os estudos foram analisados e classificados segundo a hierarquia dos níveis de evidência Grading of Recommendations Assessment, Development and Evaluations $(\mathrm{GRADE})^{42}$.

A confiabilidade entre os examinadores foi mensurada com a função kappa ${ }^{43}$. Os cálculos resultaram em um valor de Kappa de 0,9 cujo resultado é considerado excelente.

\section{RESULTADOS}

Com base nas estratégias definidas para a busca, foram identificadas 483 publicaçôes, das quais 417 foram excluídas pelos revisores após a leitura dos títulos e resumos, permanecendo 66 artigos.

Depois de removidas as duplicatas ( $\mathrm{n}=22)$, os 44 artigos remanescentes foram avaliados em etapas, excluindo as revisóes, estudos não relacionados com a síndrome mão-pé e estudos sem acesso na íntegra (resumos), e ainda aqueles que náo se enquadravam aos objetivos propostos para o estudo, possibilitando a inclusão de 29 estudos com um total de 2.433 pacientes (Figura 1 ).

Os estudos dispersaram em vários periódicos com publicaçôes por meio de ensaio clínico randomizado $(\mathrm{n}=6 ; 20,69 \%)$; caso-controle $(\mathrm{n}=1 ; 3,45 \%)$; estudo observacional retrospectivo $(\mathrm{n}=2 ; 6,90 \%)$; série de casos $(\mathrm{n}=5 ; 17,24 \%)$ e relatos de casos $(\mathrm{n}=15 ; 51,72 \%)$. Não foram encontrados estudos qualitativos avaliando a percepção das pessoas acometidas por síndrome mão-pé ou estudos com aprofundamento da causa dessa reação adversa. A Ásia foi o continente de origem da maioria dos artigos incluídos na pesquisa $(\mathrm{n}=13 ; 44,83 \%)$ com contribuiçốes do Japão $(n=3 ; 10,34 \%)$, China $(n=3$; 10,34\%), Índia ( $\mathrm{n}=3 ; 10,34 \%)$, Líbano $(\mathrm{n}=2 ; 6,90 \%)$ e Turquia ( $\mathrm{n}=2 ; 6,90 \%)$; seguido da Europa $(\mathrm{n}=7 ; 24,14 \%)$, com contribuiçôes da Alemanha $(\mathrm{n}=3 ; 10,34 \%)$, Inglaterra $(n=1 ; 3,45 \%)$, Itália $(n=1 ; 3,45 \%)$ e França ( $\mathrm{n}=2 ; 6,90 \%)$; América do Norte, com contribuiçóes dos Estados Unidos ( $\mathrm{n}=6 ; 20,69 \%)$; e Oceania e América do Sul, cujas contribuiçôes foram Austrália $(n=1 ; 3,45 \%)$ e Brasil ( $n=2 ; 6,90 \%)$, equivalente a $10,34 \%$. Não houve artigo selecionado de países da África.

A maioria dos estudos $(24 ; 82,76 \%)$ foi publicada entre os anos de 2010 e 2017.

\section{CARACTERÍSTICAS DOS ESTUDOS INCLUÍDOS}

A Tabela 1 mostra as características dos artigos incluídos quanto ao desenho do estudo, o número de participantes e sua média de idade, além do nível de evidência dos artigos que integram esta revisão. A classificaçáo da evidência foi realizada de acordo com a qualidade do estudo e os riscos de vieses. Entre esses estudos, estão contempladas as publicaçôes relacionadas à prevenção e ao tratamento da síndrome mão-pé com estudos bem delineados e dentro dos critérios estabelecidos para investigação científica. A seguir, seguem os subtítulos desses artigos e os seus respectivos resultados.

\section{CRIOTERAPIA NA PREVENÇÃO DA TOXICIDADE EM UNHAS E MÃOS INDUZIDA POR DOCETAXEL}

Dois estudos compararam a efetividade da crioterapia nas mãos de pacientes com toxicidade em unhas induzida por docetaxel. No primeiro estudo ${ }^{13}$, os pesquisadores demonstraram o uso de luvas gelatinosas congeladas para prevenção de toxicidade de unhas em mãos, induzida por docetaxel em pacientes com câncer. Dos 53 participantes do estudo, em virtude da alta taxa de desconforto durante o uso das luvas, apenas 21 apresentaram dados suficientes para avaliação. Ao realizar as análises, nenhum participante demonstrou diferença na toxicidade entre mãos enluvadas e não enluvadas. A crioterapia não pareceu reduzir a incidência, a gravidade e o tempo para toxicidade cutânea induzida por docetaxel.

No segundo estudo ${ }^{14}$, os 45 pacientes que usaram a luva congelada foram avaliados quanto à onicólise e à toxicidade cutânea. A onicólise variou de $89 \%$ versus $49 \%$ (grau 0 ) e de $11 \%$ a $51 \%$ (grau 1 a 2), respectivamente. Os resultados encontrados foram significativos na mão protegida pela luva congelada em comparação com a mão 


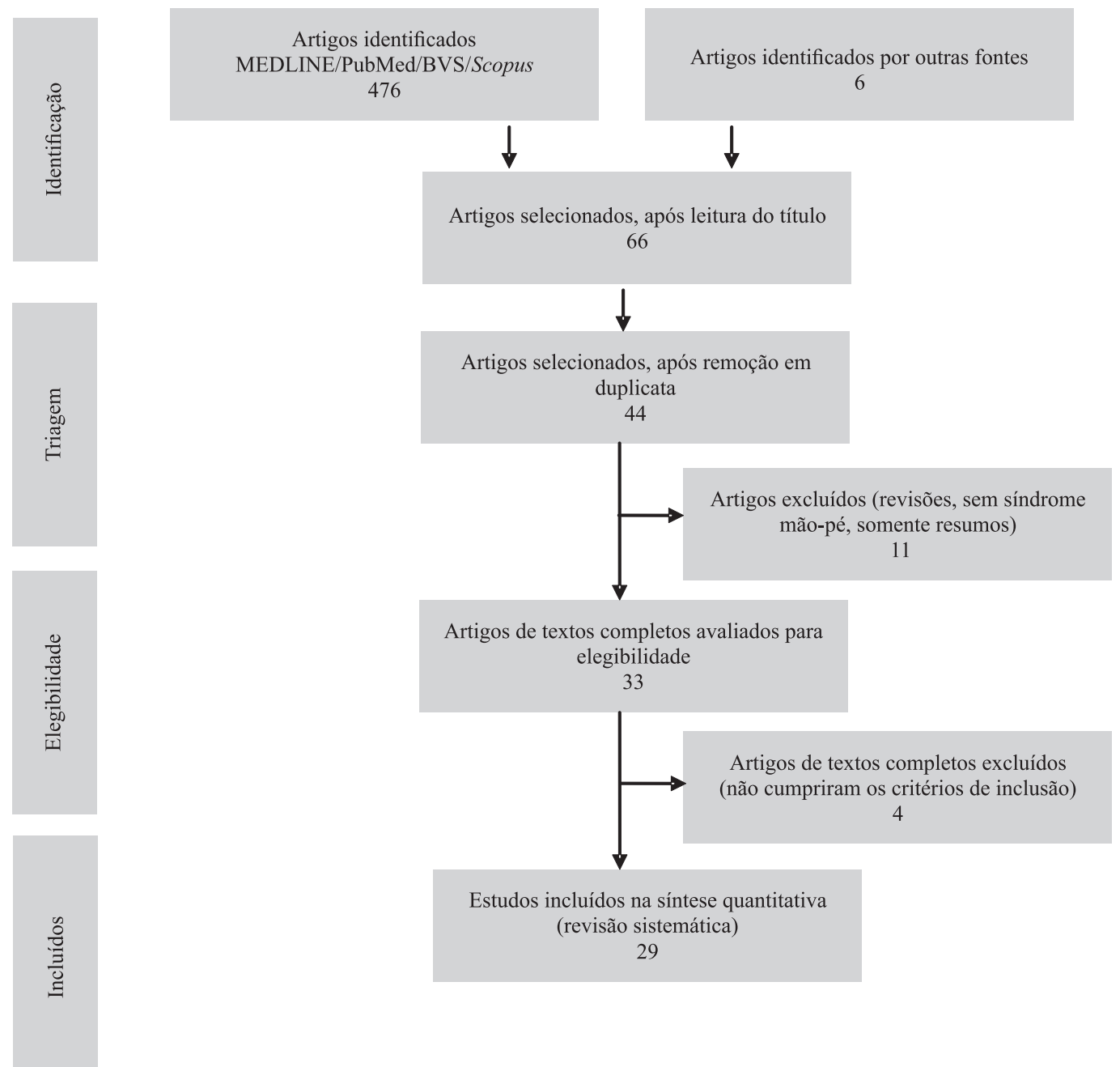

Figura 1. Fluxograma do processo de seleção dos artigos nas diferentes fases da revisão sistemática

controle ( $\mathrm{p}<0,0001)$. Ocorreu uma toxicidade da pele de $73 \%$ versus $41 \%$ (grau 0 ) e de $27 \%$ versus $59 \%$ (grau 1 a 2), respectivamente. O tempo mediano para a ocorrência de toxicidade de unha e pele não foram significativos na comparação entre a mão protegida por luva congelada em relaçấo ao controle (106 versus 58 dias para toxicidade ungueal; 57 versus 58 dias para toxicidade cutânea).

\section{PREVENÇÃO DA SÍNDROME MÃO-PÉ INDUZIDA POR QUIMIOTERAPIA COM USO DA PIRIDOXINA}

Dois estudos avaliaram o uso da piridoxina na prevenção da síndrome máo-pé. No primeiro estudo ${ }^{15}$, randomizado e duplo-cego, os pesquisadores compararam a piridoxina com placebo na prevençáo de sindrome mão-pé induzida por doxorrubicina lipossomal peguilada. Os participantes do estudo foram estratificados pelo diagnóstico do câncer: ovário, mama e endométrio, e randomizados em grupo A $(n=18)$ e grupo $B(n=16)$. Os do grupo A receberam piridoxina duas vezes ao dia $\mathrm{e}$ os participantes do grupo $\mathrm{B}$, placebo em dias alternados associado à educação em saúde relacionada à síndrome mão-pé. $\mathrm{O}$ estudo concluiu que o uso da piridoxina 100 $\mathrm{mg}$ duas vezes ao dia em dias alternados não impediu o surgimento da síndrome mão-pé.

No segundo estudo ${ }^{16}$, o objetivo foi observar o efeito de "Tao-hong-si-wu-Tang", uma preparação utilizada na medicina tradicional chinesa, comparada com piridoxina em pacientes que apresentaram síndrome mão-pé induzida por capecitabina, sorafenibe e gefitinibe, utilizados no tratamento do tumor gástrico, pulmão, mama e câncer retal. A preparação "Tao-hong-si-wu-Tang" era composta por Taoren (Semen Persicae) $30 \mathrm{~g}$, Honghua (Flos Carthami) 30 g, Shudihuang (Radix Rehmanniae Praepara-ta) 30 g, Danggui (Radix Angélica Sinensis) $30 \mathrm{~g}$, Chuanxiong (Rhizoma Chuanxiong) $15 \mathrm{~g}$, Baishao (Radix Paeoniae Alba) 15 g, Guizhi (Ramulus Cinnamomi) 15g, Chuanniuxi (Radix Cyathulae) 15 g, Gancao (Radix Glycyrrhizae) 6 g e Dazao (Fructus Jujubae) três peças. Os participantes foram distribuídos aleatoriamente em dois grupos A e B. 
Os participantes do grupo A receberam a decocção de "Tao-hong-si-wu-Tang", encharcando as mãos e os pés por 30 minutos uma vez ao dia. O grupo B recebeu 100 mg de piridoxina por via oral, duas vezes ao dia. Após um tratamento de duas semanas, o efeito terapêutico foi avaliado pelos pesquisadores, baseando-se em três sintomas principais: dor, ulceração e atrofia muscular. Foi encontrada diferença estatisticamente significativa entre os dois grupos quanto ao alívio da dor e melhora da vida cotidiana $(\mathrm{p}<0,01)$. Após as duas semanas de tratamento, a taxa efetiva foi de $88,3 \%$ no grupo $\mathrm{A}$, e maior que $50 \%$ no grupo B. Concluiu-se com este estudo que a decocçấo de "Tao-hong-si-wu-Tang" modificada é efetiva no tratamento de pacientes com síndrome mão-pé.

\section{USO DE UREIA NA PREVENÇ̃̃O DA SÍNDROME MÃO-PÉ}

Dois estudos analisaram o uso de ureia na prevenção da síndrome mão-pé. Um deles comparou o uso de creme mapisal versus creme de ureia para profilaxia de síndrome máo-pé associada à capecitabina ${ }^{17}$. $\mathrm{O}$ produto mapisal é uma pomada contendo uma grande variedade de antioxidantes e extratos de óleos nutritivos. O estudo justifica o uso de antioxidantes considerando que, durante a manifestação da síndrome mão-pé, ocorra um declínio na capacidade antioxidante da pele ${ }^{17}$. Trata-se de um estudo randomizado de fase III, em que 152 pacientes foram avaliados e, destes, 47 desenvolveram síndrome mão-pé; $39,5 \%$ foram pacientes em uso de mapisal e $22,4 \%$ em uso de ureia a $10 \%$. Os autores concluíram que o uso de creme de ureia $10 \%$ para prevenção de síndrome mão-pé é superior ao uso do creme mapisal.

O estudo randomizado e aberto de Ren et al..$^{18}$ avaliou o benefício do creme à base de ureia na profilaxia da reação cutânea mão-pé induzida pelo sorafenibe em pacientes com carcinoma hepatocelular avançado, no qual 871 pacientes foram tratados com $10 \%$ de creme à base de ureia três vezes ao dia, associado aos cuidados usuais $(\mathrm{n}=439)$, ou somente os cuidados usuais de suporte excluindo todos os cremes ( $\mathrm{n}=432)$. A avaliação da síndrome mão-pé foi feita a cada duas semanas até a $14^{\mathrm{a}}$ semana. Uma vez que a síndrome ocorreu, os pacientes receberam qualquer creme, incluindo o creme à base de ureia.

Esse estudo ${ }^{18}$ utilizou um sistema de classificação modificado específico para sintomas de síndrome mão-pé para interpretação dos resultados. De acordo com a classificação proposta, a escala Grau 1 é descrita como: entorpecimento, disestesia e/ou parestesia, formigamento, edema sem dor ou eritema das mãos e/ou pés e/ou desconforto, o que não interrompe atividades normais; Grau 2: eritema doloroso e edema das mãos e/ou pés e/ou desconforto que afetam as atividades do paciente; e Grau 3: descamação úmida, ulceração, bolhas ou dor nas mãos e/ou pés e/ou desconforto, que faz com que o paciente não possa trabalhar ou realizar atividades da vida diária. Após 12 semanas, a incidência de síndrome máo-pé em qualquer grau induzida por sorafenibe foi menor, com significância estatística no grupo que usou o creme à base de ureia versus o grupo de pacientes que receberam os cuidados de suporte apenas $(56,0 \%$ versus $73,6 \%$, respectivamente; odds ratio [OR], 0,457, 95\% IC, 0,344-0,608; $\mathrm{p}<0,001$ ); assim como a incidência de grau $\geq 2$ hand-foot skin reaction ( $20,7 \%$ versus $29,2 \%$, respectivamente; OR, 0,$635 ; 95 \%$ IC, 0,466 a 0,$866 ; p=0,004)$.

\section{PIRIDOXINA E UREIA: PREVENÇÃO E TRATAMENTO}

Um estudo avaliou o uso de piridoxina para profilaxia da síndrome mão-pé entre 38 pacientes com câncer de mama metastático em uso de capecitabina ${ }^{19} \mathrm{e}$ comparou com dados históricos de 40 pacientes tratados com capecitabina e sem uso da piridoxina.

Os autores mostraram que o uso de piridoxina pode reduzir o risco de desenvolver síndrome mão-pé de alto grau $(\mathrm{p}<0,01)$. Os pesquisadores avaliaram também o uso do creme de ureia, aplicada na primeira aparição de síndrome mão-pé, e mostraram que a pomada de ureia parece reduzir tanto a probabilidade de desenvolver a síndrome mão-pé como impede a exacerbação para um grau mais grave.

\section{USO DE BLOQUEADORES H2 ASSOCIADOS A TAXOIDESE INCIDÊNCIA DE SÍNDROME MÃO-PÉ}

Kawaguchi et al. ${ }^{20}$ incluíram 993 pacientes de 20 instituiçóes a fim de avaliar o uso de bloqueadores H2 (ranitidina, lafutidina) em pacientes em uso de docetaxel, avaliando a síndrome mão-pé. $\mathrm{O}$ efeito inibitório dos antagonistas dos receptores $\mathrm{H} 2$ associados com docetaxel aumentaram a incidência da toxicidade cutânea de síndrome mão-pé grau 2 e eritema facial. Isso foi demonstrado por duas análises de regressão logística multivariada. A lafutidina influenciou mais a incidência de síndrome mão-pé e eritema facial. A ranitidina apresentou uma menor influência, embora mantivesse resultado significativo sobre a incidência de síndrome mão-pé e eritema facial (OR 2,58; $\mathrm{p}=0,029)$. Isso é explicado porque a depuração do docetaxel é mediada pela isoenzima CYP3A4 cujo sítio ativo é inibido por inibidores $\mathrm{H} 2$ do tipo da ranitidina, aumentando assim a incidência de síndrome mão-pé.

\section{HIDROTERAPIA: TRATAMENTO DE SÍNDROME MÃO-PÉ PERSISTENTE APÓS QUIMIOTERAPIA}

Estudo prospectivo, randomizado, multicêntrico e controlado, realizado por Dalenc et al. ${ }^{21}$, aplicou a hidroterapia em pacientes após o tratamento do câncer de mama não metastático. No estudo, foi investigada a 
eficácia da hidroterapia como tratamento de suporte para o manejo de reaçóes adversas dermatológicas persistentes e duradouras, induzidas por terapia neoadjuvante.

Dois grupos de pacientes foram randomizados. Adotaram-se como critérios de inclusão mulheres com idade $\geq 18$ anos, em remissão completa após tratamento combinado com quimioterapia neoadjuvante (paclitaxel e docetaxel), cirurgia (incluindo cirurgia conservadora ou mastectomia com dissecçáo linfonodal axilar ou sentinela) e radioterapia para tratamento de carcinoma de mama infiltrante receptor de estrógeno e progesterona positivo e HER 2 negativo. As mulheres também deveriam estar em terapia hormonal adjuvante com um inibidor da aromatase ou tamoxifeno, com ou sem agonista do hormônio liberador de hormônio luteinizante. Os pacientes deveriam, ainda, apresentar pelo menos dois eventos adversos dermatológicos graduados $\geq 1$ usando o NCI-CTCAE versão 4.02: pele seca, perda de unha, dor, prurido, hiperpigmentação da pele, endurecimento da pele, dermatite de radiaçáo e linfedema. Todos foram incluídos dentro de uma janela de uma a cinco semanas após o término da radioterapia.

O grupo-controle $(n=33)$ recebeu os cuidados de suporte de rotina e o grupo de tratamento $(\mathrm{n}=35)$ recebeu três semanas de hidroterapia específica. $\mathrm{O}$ tratamento com a hidroterapia consistiu de um regime alternativo de cuidados diários incluindo: (1) banhos durante 20 minutos no máximo, à temperatura de $34^{\circ} \mathrm{C}$ para proporcionar um efeito emoliente e anti-inflamatório; (2) banho de chuveiro durante 5 minutos para facilitar a remoção de escamas amolecidas durante o banho, seguido de pulverização com água termal e névoa, a fim de melhorar os efeitos antipruriginosos e calmantes do tratamento térmico; (3) ingestão oral de água termal e associada a todos os tratamentos térmicos; (4) envolvimento da pele com uma espessa camada de filme emoliente e oclusiva para melhorar a hidratação da pele; (5) massagens específicas realizadas por um fisioterapeuta para amaciar a pele e o tecido cicatricial e assim reduzir o edema e também linfedema pós-operatório; (6) cuidado estético em uma oficina de maquiagem por um especialista para aprender a esconder cicatrizes corporais e faciais e marcas persistentes na pele.

A maioria dos itens avaliados apresentou resultados significativos no grupo de intervençáo com hidroterapia versus o grupo-controle conforme descrito: qualidade de vida em relação ao câncer de mama $(\mathrm{p}=0,0001)$; qualidade de vida dermatológica $(p=0,0015)$, reaçóes adversas $(\mathrm{p}=0,0044)$ e imagem corporal $(\mathrm{p}=0,0139)$.

A seguir, serão apresentados 15 relatos e cinco séries de casos que incluíram a ocorrência da síndrome mão-pé em pacientes em uso de quimioterapia. $\mathrm{Na}$ Tabela 2 , estão contempladas publicaçóes com indicadores que auxiliam o profissional a identificar a síndrome mão-pé e o perfil do agente indutor e, na Tabela 3, as publicações relacionadas às estratégias de tratamento.

\section{SÉRIES E RELATOS DE CASOS}

Em uma das séries ${ }^{22}$, os pesquisadores observaram o evento da síndrome máo-pé em cinco pacientes após o uso de doxorrubicina e ciclofosfamida, seguido de um taxoide em dose densa ${ }^{22}$ cujo tratamento necessitou do uso de pegfilgrastim. Entre os casos, destacou-se o de uma paciente em tratamento para o câncer de mama. A paciente desenvolveu síndrome mão-pé após dois dias da primeira dose de paclitaxel. Iniciou com uma sensação de formigamento e queimação nas palmas das mãos e nos calcanhares, em ambos os lados do corpo, posteriormente evoluindo com descamação, rachaduras na pele e bolhas nos pés, assim como o edema. A maioria das lesãos recuperou após oito semanas. Uma segunda paciente desenvolveu vermelhidáo, sensibilidade e rachaduras envolvendo mãos e pés, mesmo com suporte e uso de bolsa de gelo nas mãos e pés durante as infusôes da quimioterapia.

Farhat et al. ${ }^{23}$ relataram cinco casos de pacientes que desenvolveram síndrome mão-pé em tratamento com docetaxel. Em todos os casos, a conduta foi a interrupção do tratamento com docetaxel.

Em outros cinco casos $^{24}$ de pacientes com câncer de mama metastático em tratamento com capecitabina e docetaxel que desenvolveram síndrome mão-pé, o tratamento de escolha foi a vitamina E com resolução das manifestaçóes da síndrome em todos os casos ${ }^{24}$.

Chew e Chuen ${ }^{25}$ relataram quatro casos de pacientes que apresentaram reaçóes cutâneas após tratamento semanal com docetaxel. Uma das pacientes recebeu como tratamento creme de hidrocortisona, cloxacilina oral e aconselhamento para compressas frias no local das lesôes; outra paciente tratou com cloxacilina oral e pomada de mupirocina; a terceira paciente tratou com creme de propionato de clobetasol e a quarta recebeu a combinação de dipropionato de betametasona a $0,05 \%$, clotrimazol a $1 \%$ e sulfato de gentamicina a $0,1 \%$. Todas as pacientes prosseguiram com a quimioterapia com melhora da reação cutânea.

$\mathrm{Na}$ série publicada por Wang et al. ${ }^{26}$, três mulheres desenvolveram erupções cutâneas nas mãos e pés durante o tratamento quimioterápico. Achados de exames físicos sugeriram infecção por tinea, uma vez que se espalharam para palmas das mãos e plantas dos pés, com borda eritematosa, escamosa e progressiva, seguida de espessamento e descoloraçáo das unhas, sugestivos de onicomicose. Essas pacientes foram submetidas a exames 
Tabela 2. Descrição dos indicadores da síndrome mão-pé

\begin{tabular}{|c|c|c|c|}
\hline Autor, ano & Sinais e sintomas & Localização no corpo & Medicamento indutor \\
\hline Bardia et al., $2006^{22}$ & $\begin{array}{l}\text { Formigamento, queimação, } \\
\text { vermelhidão, perda da } \\
\text { sensibilidade, rachaduras } \\
\text { e descamação; edema e } \\
\text { bolhas }\end{array}$ & $\begin{array}{l}\text { Palmas das mãos e dos } \\
\text { calcanhares; bolhas nos pés }\end{array}$ & $\begin{array}{l}\text { ACT (paclitaxel); ACT } \\
\text { (docetaxel); docetaxel }\end{array}$ \\
\hline Farhat et al., $2008^{23}$ & $\begin{array}{l}\text { Prurido intenso, queimação, } \\
\text { edema e eritema facial e } \\
\text { pescoço. Eritema cutâneo e } \\
\text { ardor com descamação }\end{array}$ & $\begin{array}{l}\text { Palmas das mãos e sola dos } \\
\text { pés; face e pescoço }\end{array}$ & $\begin{array}{l}\text { FEC (fluoruracila, epirrubicina } \\
\text { e ciclofosfamida) e docetaxel; } \\
\text { ACT (docetaxel) e filgrastima }\end{array}$ \\
\hline Kara et al., $2006^{24}$ & $\begin{array}{l}\text { Lesões cutâneas } \\
\text { descamativas }\end{array}$ & Pele, mão e unhas & $\begin{array}{l}\text { Docetaxel, capecitabina e } \\
\text { ácido zoledrônico }\end{array}$ \\
\hline Chew e Chuen, $2009^{25}$ & $\begin{array}{l}\text { Placa eritematosa, } \\
\text { dor, ardor e formação } \\
\text { de bolhas; comichão, } \\
\text { lesões eritematosas com } \\
\text { descamação }\end{array}$ & Dorso e punhos das mãos & $\begin{array}{l}\text { Docetaxel; docetaxel+ } \\
\text { carboplatina; docetaxel+ } \\
\text { capecitabina; doxorrubicina } \\
\text { lipossômica }\end{array}$ \\
\hline Wang et al., $2016^{26}$ & $\begin{array}{l}\text { Descamação, dor e } \\
\text { prurido e eritema; fissuras, } \\
\text { rachaduras e sangramento } \\
\text { de áreas acometidas; } \\
\text { pápulas eritematosas; lesão } \\
\text { ungueal }\end{array}$ & $\begin{array}{l}\text { Dedos, mãos e pés; } \\
\text { tornozelos e pernas; unhas } \\
\text { espessas, escuras e/ou } \\
\text { amareladas }\end{array}$ & $\begin{array}{l}\text { ACT (paclitaxel); capecitabina; } \\
\text { doxorrubicina lipossômica }\end{array}$ \\
\hline Corazza et al., $2014^{27}$ & $\begin{array}{l}\text { Múltiplas placas e manchas; } \\
\text { dor, ardência, edema, } \\
\text { eritema, hiperpigmentação }\end{array}$ & $\begin{array}{l}\text { Dorso e palma das mãos; } \\
\text { dorso e superfície lateral } \\
\text { dos pés, axilas e lado } \\
\text { interno das coxas }\end{array}$ & Docetaxel \\
\hline Richards et al., $2012^{28}$ & $\begin{array}{l}\text { Eritema, edema, dor e } \\
\text { perda da sensibilidade }\end{array}$ & Pele das mãos e pés & Paclitaxel \\
\hline $\begin{array}{l}\text { Housholder et al., } \\
2012^{29}\end{array}$ & $\begin{array}{l}\text { Erupção, prurido, dor, } \\
\text { edema, telangiectasias e } \\
\text { cutículas eriçadas }\end{array}$ & $\begin{array}{l}\text { Dorso das mãos, unhas } \\
\text { proximais e cutículas }\end{array}$ & Paclitaxel \\
\hline Ozkol et al., $2016^{30}$ & $\begin{array}{l}\text { Eritema, dor, edema, } \\
\text { hiperpigmentação e } \\
\text { descamação }\end{array}$ & $\begin{array}{l}\text { Palma das mãos, planta dos } \\
\text { pés, face e pescoço }\end{array}$ & Docetaxel \\
\hline Sauter et al., $2007^{31}$ & $\begin{array}{l}\text { Parestesia, edema, dor, } \\
\text { bolhas, ulceração }\end{array}$ & $\begin{array}{l}\text { Pontas dos dedos distais da } \\
\text { mão }\end{array}$ & Capecitabina \\
\hline Braghiroli et al., $2017^{33}$ & $\begin{array}{l}\text { Edema, eritema, } \\
\text { descamação, ulceração, } \\
\text { vesicopústulas e sensação } \\
\text { de queimação }\end{array}$ & Mãos, punhos, pernas e pés & Trastuzumabe e paclitaxel \\
\hline Jung et al., $2015^{34}$ & $\begin{array}{l}\text { Formigamento, prurido, } \\
\text { eritema, dor, erupção } \\
\text { maculopapular, erosões e } \\
\text { lesões na pele infraesternal }\end{array}$ & $\begin{array}{l}\text { Pontas dos dedos das mãos } \\
\text { e planta dorsal e medial } \\
\text { do pé direito; cotovelos e } \\
\text { braços, costas e coxa dorsal }\end{array}$ & Doxorrubicina peguilato \\
\hline Qiao et al., $2012^{35}$ & $\begin{array}{l}\text { Eritema, edema e dor em } \\
\text { lesões na pele infraesternal }\end{array}$ & $\begin{array}{l}\text { Palmas das mãos e solas } \\
\text { dos pés }\end{array}$ & Capecitabina \\
\hline Katoh et al., $2004^{36}$ & $\begin{array}{l}\text { Dor, formigamento, } \\
\text { eritema, edema }\end{array}$ & $\begin{array}{l}\text { Mãos, planta dos pés e } \\
\text { rosto }\end{array}$ & Docetaxel \\
\hline $\begin{array}{l}\text { Gurumurthi et al., } \\
2013^{37}\end{array}$ & $\begin{array}{l}\text { Lesões, dor, eritema, } \\
\text { formigamento, edema }\end{array}$ & $\begin{array}{l}\text { Pele, palmas das mãos, sola } \\
\text { dos pés }\end{array}$ & Docetaxel \\
\hline
\end{tabular}


Tabela 3. Estratégias de tratamento medicamentoso para síndrome mão-pé

\begin{tabular}{|c|c|c|}
\hline Autor, ano & Tratamento proposto & Desfecho \\
\hline $\begin{array}{l}\text { Bardia et al., } \\
2006^{22}\end{array}$ & Analgésicos e curativos úmidos; bolsas de gelo & $\begin{array}{l}\text { Lesões de pele foram recuperadas em } 8 \\
\text { semanas }\end{array}$ \\
\hline $\begin{array}{l}\text { Corazza et al., } \\
2014^{27}\end{array}$ & $\begin{array}{l}\text { Multivitamínico EV, emoliente tópico e esteroide } \\
\text { tópico }\end{array}$ & $\begin{array}{l}\text { Sintomas começaram a desaparecer quatro } \\
\text { dias após o início do tratamento }\end{array}$ \\
\hline $\begin{array}{l}\text { Richards et al., } \\
2012^{28}\end{array}$ & $\begin{array}{l}\text { Sulfadiazina de prata tópica para áreas abertas da } \\
\text { ferida, triancinolona e emoliência }\end{array}$ & $\begin{array}{l}\text { Um mês após a conclusão do regime de } \\
\text { paclitaxel ocorreu a resolução das placas }\end{array}$ \\
\hline $\begin{array}{l}\text { Housholder et } \\
\text { al., } 2012^{29}\end{array}$ & $\begin{array}{l}\text { Pomada de propionato de clobetasol; duas vezes } \\
\text { ao dia em ambas as mãos }\end{array}$ & $\begin{array}{l}\text { Erupção melhorou em } 1 \text { mês com o uso de } \\
\text { pomada }\end{array}$ \\
\hline $\begin{array}{l}\text { Ozkol et al., } \\
2016^{30}\end{array}$ & $\begin{array}{l}\text { 1- Prednisolona } 40 \mathrm{mg} / \mathrm{dia} \text { ( } 1-4 \text { dias) } \\
\text { 2- Feniramina } 22,75 \mathrm{mg} / \mathrm{mL} / \mathrm{dia}, 4 x \text { dia (2-4 dias) } \\
\text { 3- Furoato de mometasona tópico, } 2 x \text { dia (3-10 dias) } \\
\text { 4- Ureia tópico } 2 x \text { dia (4-10 dias) }\end{array}$ & $\begin{array}{l}\text { No } 7^{\circ} \text { dia de tratamento, o edema e o } \\
\text { eritema diminuíram }\end{array}$ \\
\hline $\begin{array}{l}\text { Sauter et al., } \\
2007^{31}\end{array}$ & Ligaduras de gaze com fucidina & Cicatrização local completa \\
\hline $\begin{array}{l}\text { Akoglu et al., } \\
2014^{32}\end{array}$ & $\begin{array}{l}\text { Esteroides tópicos, piridoxina oral }(250 \mathrm{mg} / \mathrm{dia}) \text {; } \\
\text { elevação das extremidades durante a infusão e } \\
\text { aplicação de compressa fria }\end{array}$ & $\begin{array}{l}\text { As lesões regrediram por completo } \\
\text { após } 1 \text { semana; sintomas de disestesia } \\
\text { mantiveram }\end{array}$ \\
\hline $\begin{array}{l}\text { Braghiroli et } \\
\text { al., } 2017^{33}\end{array}$ & $\begin{array}{l}\text { Suspensão da quimioterapia e administração } \\
\text { de opioides e prednisona }(0,5 \mathrm{mg} / \mathrm{kg}) \text { além } \\
\text { de compressas de permanganato de potássio e } \\
\text { aplicação de curativo oclusivo com fludroxicortide }\end{array}$ & $\begin{array}{l}\text { Após cinco dias ocorreu melhora } \\
\text { significativa da dor e das lesões }\end{array}$ \\
\hline $\begin{array}{l}\text { Jung et al., } \\
2015^{34}\end{array}$ & Antioxidante (Mapisal $^{\circledR}$ ) - $3 x$ dia, durante 3 dias & $\begin{array}{l}\text { Os sintomas passaram de grau } 3 \text { para } \\
\text { graus } 1-2 \text {. As lesões da pele infraesternal } \\
\text { desapareceram após } 1 \text { semana do } \\
\text { tratamento local }\end{array}$ \\
\hline $\begin{array}{l}\text { Qiao et al., } \\
2012^{35}\end{array}$ & Ureia tópico & $\begin{array}{l}\text { Os sintomas passaram de grau } 3 \text { para } \\
\text { graus } 1-2 \text {. As lesões da pele infraesternal } \\
\text { desapareceram após } 1 \text { semana do } \\
\text { tratamento local }\end{array}$ \\
\hline $\begin{array}{l}\text { Gurumurthi et } \\
\text { al., } 2013^{37}\end{array}$ & Esteroides parenterais & $\begin{array}{l}\text { Os sintomas foram resolvidos após quatro } \\
\text { dias e o regime de quimioterapia }\end{array}$ \\
\hline $\begin{array}{l}\text { Hoesly et al., } \\
2011^{38}\end{array}$ & $\begin{array}{l}\text { Creme de fluocinonida } 0,05 \% \text {; creme de lactato } \\
\text { de amônio } 12 \% \text {; pomada de mupirocina, } \\
\text { creme econazol e ciprofloxacina oral. O uso da } \\
\text { ciprofloxacina foi por conta de uma suspeita clínica } \\
\text { de superinfecção cutânea e história de paroníquia } \\
\text { por Pseudomonas aeruginosa }\end{array}$ & $\begin{array}{l}\text { A superinfecção por Pseudomonas spp. } \\
\text { pós síndrome mão-pé foi considerada } \\
\text { a fonte mais provável de sepse, } \\
\text { embora os resultados das hemoculturas } \\
\text { permaneceram negativos. Apesar } \\
\text { da antibioticoterapia endovenosa de } \\
\text { amplo espectro e medidas agressivas de } \\
\text { ressuscitação, a paciente morreu em menos } \\
\text { de } 24 \text { horas }\end{array}$ \\
\hline $\begin{array}{l}\text { Jain et al., } \\
2012^{39}\end{array}$ & Emolientes e analgésicos & $\begin{array}{l}\text { O tratamento sintomático da síndrome } \\
\text { mão-pé foi satisfatório e os ciclos } \\
\text { adicionais de docetaxel foram continuados } \\
\text { no intervalo usual sem agravamento } \\
\text { adicional das lesões }\end{array}$ \\
\hline $\begin{array}{l}\text { Assi et al., } \\
2013^{40}\end{array}$ & $\begin{array}{l}\text { Instrução para usar mangas compridas e cobrir as } \\
\text { áreas expostas ao sol do rosto e pescoço, seguido } \\
\text { de aplicação de protetor solar e cremes hidratantes }\end{array}$ & $\begin{array}{l}\text { Ocorreu melhora após } 1 \text { semana e o } \\
\text { tratamento quimioterápico reestabelecido } \\
\text { como planejado. Os sintomas da pele } \\
\text { estabilizaram e diminuíram em tamanho }\end{array}$ \\
\hline $\begin{array}{l}\text { Simão et al., } \\
2012^{41}\end{array}$ & Creme de aloe vera $3 \mathrm{x}$ ao dia & $\begin{array}{l}\text { Regressão da síndrome mão-pé em } 10 \\
\text { dias após o início do tratamento; melhoria } \\
\text { da qualidade de vida e retomada do } \\
\text { tratamento quimioterápico }\end{array}$ \\
\hline
\end{tabular}


laboratoriais para análise micológica das lesôes. Nos três casos, no exame direto para fungos, observaram-se hifas ramificadas e, na cultura do material de duas das pacientes, houve crescimento de Trichophyton rubrum. As pacientes foram tratadas com antifúngicos: terbinafina, econazol e fluconazol. Essa conduta permitiu a continuidade do tratamento quimioterápico. Para os autores, é importante diagnosticar os casos de infecçôes fúngicas associadas à síndrome mão-pé, a fim de orientar o tratamento adequado.

Os relatos de casos incluíram 15 pacientes ${ }^{27-41}$ que desenvolveram síndrome mão-pé. Dez pacientes receberam tratamento à base de taxanos (docetaxel ou paclitaxel); a capecitabina estava presente no tratamento de quatro desses pacientes. A conduta predominante nos casos foi a suspensão da infusão da quimioterapia, seguido do uso de corticosteroides tópicos, piridoxina oral, sulfadiazina de prata, creme à base de ureia e de aloe vera. Também foram citados o uso de compressas frias e a elevação das extremidades durante a infusão na tentativa de aumentar a tolerância da quimioterapia e impedir a indução da síndrome mão-pé.

\section{DISCUSSÃO}

A identificação da síndrome mão-pé passa desapercebida por vários profissionais da equipe. Os pacientes apresentam sinais e sintomas, como disestesia, sensação de formigamento, queimaçáo, dor, eritema, edema, descamação da pele, seguida da formação de bolhas com dor e prurido que, após descontinuada, abrem lesóes. Geralmente, ocorrem nas mãos e pés, no entanto, outras partes do corpo também podem ser acometidas, como pescoço, axilas, espaço intraesterno, virilhas, pernas, tórax e tronco ${ }^{27}$. Entre vários fármacos indutores da síndrome mão-pé, nesta revisão, os taxanes foram contemplados em $50 \%$ das publicaçóes de relatos de casos.

Nos 29 estudos identificados nesta revisão sistemática, $\mathrm{n}=26(90 \%)$ apresentaram alternativas de tratamento e/ou prevenção, tanto farmacológico como não farmacológico, para pacientes acometidos com a síndrome mãopé $^{15-20,22-32}$. A maioria dos manejos para tratamento da síndrome mão-pé publicados foi de relatos de casos. Nas opçóes de tratamento com o uso de fármacos, a posologia, a duração do tratamento e o desfecho variaram muito entre os estudos.

A crioterapia, no estudo de Scotté at al. ${ }^{14}$, apresentou eficácia na prevenção da síndrome mão-pé, visto que, quando aplicada em certas áreas-alvo, como as mãos, promove vasoconstrição, que favorece à redução dos agentes tóxicos no sítio tratado ${ }^{44}$. Esta também foi apresentada nos relatos das séries de casos, embora a aplicação nas áreas afetadas pela síndrome mão-pé tenha sido realizada com bolsa de gelo ${ }^{22}$. O gelo, além de promover vasoconstrição, tem ação anti-inflamatória e reduz também o edema, pois facilita a oxigenaçáo celular, contribuindo com redução da dor ${ }^{44}$.

O uso da piridoxina (vitamina B6) na prevençáo da síndrome mão-pé demonstrou resultados controversos. von Gruenigen et al. ${ }^{15}$ demonstraram que o uso de piridoxina não foi eficaz na prevenção da síndrome mão-pé, enquanto Yoshimoto et al. ${ }^{19}$ defenderam que a piridoxina pode ser eficaz para graus mais graves quando associada ao uso de capecitabina.

O creme de ureia, nos estudos avaliados, demonstrou eficácia tanto na prevenção ${ }^{19,20}$ quanto no tratamento da síndrome máo-pé ${ }^{21}$. A ureia está entre os ativos que permitem a hidratação efetiva da pele; ou seja, é uma substância umectante. E essa propriedade lhe confere a capacidade de absorver a água do tecido ${ }^{45}$. Dessa forma, promove uma barreira epidérmica com atividade regenerativa e protetora contra agressores que promoveriam o ressecamento da pele. Tem efeito queratolítico em altas concentrações ( $\geq 20 \%$ ), por meio da interação com os corneócitos epidérmicos. E, além disso, tem a característica de permear outras substâncias ativas ${ }^{45}$.

A hidroterapia foi uma estratégia não farmacológica que apresentou bons resultados no tratamento da síndrome mão-pé23. Os benefícios encontrados com a hidroterapia incluiram ação anti-inflamatória, emoliência e hidratação.

Das publicações, $\mathrm{n}=20$ (69\%) apresentaram resultados na forma de série e de relatos de casos. Em uma das séries de $\operatorname{casos}^{26}$, os autores apresentaram a vitamina E como alternativa para tratamento com desfecho significativo. Acredita-se que sua ação esteja relacionada com suas propriedades antioxidantes, prevenindo a peroxidação de lipídeos, resultando em membranas celulares mais estáveis ${ }^{26}$.

O uso de analgésicos foi mencionado para alívio da dor na síndrome mão-pé. Os analgésicos da classe dos anti-inflamatórios não esteroides são bastante utilizados na prática clínica. A sua ação analgésica se relaciona com a inibição de prostaglandinas, substâncias que sensibilizam nociceptores cujo bloqueio promove analgesia ${ }^{46}$. Para os casos mais graves, descritos nos relatos de casos, foram utilizados anti-inflamatórios esteroides da classe dos glicocorticoides (prednisolona, mometasona, dexametasona e triancinolona). Esses agentes terapêuticos apresentam um grande potencial anti-inflamatório.

Ainda dessa classe terapêutica, o uso de clobetasol foi mencionado em um dos relatos ${ }^{31}$ como alternativa para tratamento com resoluçáo dos sintomas após um mês de uso. Entre eles, o fludoxicortide e o clobetasol foram administrados usando a técnica de curativos oclusivos. 
A sulfadiazina de prata também foi citada no tratamento da síndrome mão-pé em um dos casos. Neste, o paciente apresentava feridas abertas cuja ação bactericida foi evidenciada com sucesso ${ }^{30}$. O uso de antimicrobianos tem a intenção de prevenir complicaçôes nas lesôes, embora sejam raras, como as infecçóes por estafilococos ou bactérias gram-negativas, ou ainda de erisipela com risco de sepse ${ }^{47}$. Outros antimicrobianos como a cloxalina oral e a gentamicina a $0,1 \%$ foram utilizados e citados nos relatos de casos.

O ressecamento da pele também é comum em paciente em uso de quimioterápico. Nesta revisão, o uso de cremes hidratantes e emolientes foram apresentados como coadjuvantes das condutas para tratamento ${ }^{28-30,40,41}$. A hidratação da pele é essencial em qualquer circunstância, portanto, é imprescindível o uso de hidratantes tanto na prevençáo como no tratamento da síndrome mão-pé, pois o ressecamento causa o rompimento da barreira epidérmica e redução da água, aumentando o risco de lesóes ${ }^{48}$.

Em um dos relatos de casos, foi apresentado o tratamento com creme à base de aloe vera (babosa) ${ }^{41}$. A aloe vera possui propriedades umectantes, emolientes, anti-inflamatórias, cicatrizantes e regeneradoras de tecidos. Sugere-se que a manose-6-fosfato, principal polissacarídeo presente na aloe vera, seja responsável pela propriedade cicatrizante. A cicatrização ocorre pela estimulação direta da atividade dos macrófagos e fibroblastos. A ativação dos fibroblastos aumenta tanto a síntese do colágeno como a de proteoglicanas, promovendo assim a reparaçáo dos tecidos. O mecanismo de ação baseia-se na inibição dos produtos derivados do metabolismo do ácido araquidônico, tais como o tromboxano $\mathrm{B}$, o qual limita a produçáo de prostaglandina F2a, prevenindo a isquemia dérmica progressiva $^{41,49,50}$.

A síndrome máo-pé é uma reação adversa muito comum durante o tratamento com agentes quimioterápicos e é um fator preditor de morbidade e mortalidade, uma vez que as lesóes são portas de entrada para instalação de microrganismos e, dessa forma, implica em risco de sepse $^{29-47}$.

Sabe-se também que a dose acumulada de quimioterápico associada à baixa da imunidade propicia o risco de infecções. Entre as infecções observadas na prática clínica, estão as infecçôes fúngicas nas unhas das mãos e pés. No entanto, foi encontrado apenas um relato de caso que se referiu à onicólise e uma série de casos que abordou o caso de onicomicoses no contexto da síndrome mão-pé ${ }^{27}$. Após a confirmação da infecção fúngica por meio de exames micológicos realizados com base no raspado de lesão ungueal, o tratamento instituído foi com terbinafina, econazol e fluconazol ${ }^{27}$.
Esta revisão mostrou um panorama do que é descrito na literatura sobre a síndrome mão-pé inclusive, com a abordagem de infecçóes fúngicas manifestadas como onicomicoses, incluindo aspectos de identificação, prevenção e tratamento da síndrome mão-pé, no entanto, apresentou limitação em relação à qualidade das evidências disponíveis.

Foi realizada uma abordagem de revisão crítica da literatura, com ênfase na contribuição de cada item incluído. Como outras revisóes dessa natureza ${ }^{51}$, objetivou-se alcançar uma hipótese ainda não explorada pela comunidade científica. No entanto, a presente revisão possui todos os elementos das revisôes sistemáticas da literatura como: pergunta de pesquisa, seleçáo com cegamento por mais de um avaliador, estratégias de busca e critérios de elegibilidade para seleção dos artigos. Ainda assim, apresenta limitaçóes como a impossibilidade de realizar uma metanálise em função da qualidade heterogênea dos estudos selecionados.

Outra limitação foi a inviabilidade de acesso à base de dados europeia Embase como fonte de pesquisa (não disponível gratuitamente) prejudicando o alcance a outros artigos. Portanto, se propóe uma interpretação inovadora para os dados existentes que possibilite ampliar as pesquisas.

\section{CONCLUSÃO}

Os resultados desta revisão apontaram que a síndrome mão-pé implica prejuízo para o tratamento do câncer e comprometimento da qualidade de vida dos pacientes. Evidenciou também que, apesar de ser uma reação experimentada por vários pacientes, é pouco explorada pela comunidade científica. Em função disso, observou-se um número significativo de relatos de casos de pacientes em tratamento para o câncer. Ainda assim, os estudos observacionais e relatos de casos auxiliam a equipe multiprofissional de cuidado oncológico na identificação, prevenção e tratamento da síndrome mão-pé induzida por agentes quimioterápicos. Outro aspecto observado foi a necessidade de considerar as micoses superficiais no contexto da síndrome mão-pé, assim como as estratégias complementares de tratamento. Entretanto, são necessárias novas pesquisas com desenhos metodológicos de qualidade, estudo prospectivo quase experimental e ensaios clínicos randomizados controlados, a fim de estabelecer os estágios em que os pacientes em tratamento com agentes quimioterápicos estão mais sujeitos às infecçóes causadas por fungos. Estudos desse tipo poderão oferecer evidência científica mais robusta ao tema estudado, com possibilidade de elucidar a etiologia e definir protocolos seguros de tratamento. Protocolos 
melhor definidos, como os cuidados pessoais e a educação em saúde, poderiam ser confrontados, para que a síndrome mão-pé possa ser melhor diagnosticada e manejada.

$\mathrm{O}$ aparecimento dessa síndrome afeta a qualidade de vida das pacientes, sendo, muitas vezes, limitante das atividades de rotina. Estudos qualitativos e quantitativos precisam ser delineados, no sentido de contribuir com o manejo dos pacientes, compreender a relação da síndrome com a autoestima, com o propósito de estabelecer estratégias para a promoçáo de saúde em pacientes oncológicos, seja por meio da divulgaçáo de informaçôes, educação em saúde, promoção da saúde e treinamento da equipe multiprofissional envolvida.

\section{CONTRIBUIÇÕES}

Paulina Patente Pereira participou do projeto, da coleta de dados, da seleção dos artigos para a revisão, da análise dos dados, redação e análise crítica. Reginaldo dos Santos Pedroso participou do projeto, auxiliou na escolha dos artigos, na análise dos dados, na redação e na análise crítica. Maria Ângela Ribeiro desenhou o estudo, participou do projeto, da concepção e orientação metodológica da pesquisa, da coleta e da seleçâo dos artigos para a revisão, da análise dos dados, da redaçáo e revisão crítica. Todos os autores aprovaram a versão final a ser publicada.

\section{AGRADECIMENTOS}

À Coordenação de Aperfeiçoamento de Pessoal de Nível Superior (Capes).

\section{DECLARAÇÃO DE CONFLITOS DE INTERESSE}

Nada a declarar.

\section{FONTES DE FINANCIAMENTO}

Programa de Residência em Área Profissional da Saúde (PRAPS) do Ministério da Educação (MEC).

\section{REFERÊNCIAS}

1. Sullivan R, Pramesh CS, Booth CM. Cancer patients need better care, not just more technology. Nature. 2017;549(7672):325-328. doi: https://doi. org/10.1038/549325a

2. Ministério da Saúde (BR). Portaria no 874, de 16 de maio de 2013. [Internet]. [acesso 2018 dez. 3]. Disponível em: http://bvsms.saude.gov.br/bvs/saudelegis/gm/2013/ prt0874_16_05_2013.html

3. Allemani C, Coleman MP. Public health surveillance of cancer survival in the United States and worldwide: the contribution of the CONCORD programme. Cancer. 2017;123(Suppl 24):4977- 4981. doi: https://doi. org/10.1002/cncr.30854

4. Instituto Nacional de Câncer José Alencar Gomes da Silva. Estimativa 2018: incidência de câncer no Brasil. [Internet]. Rio de Janeiro: INCA; 2017. [acesso 2018 dez. 3]. Disponível em: http://www1.inca.gov.br/ estimativa/2018/

5. Anderson RT, Keating KN, Doll HA, et al. The handfoot skin reaction and quality of life questionnaire: an assessment tool for oncology. Oncologist. 2015;20(7):831-8. doi: https://doi.org/10.1634/ theoncologist.2014-0219

6. Nagore E, Insa A, Sanmartín O. Antineoplastic therapyinduced palmar plantar erythrodysesthesia ('hand-foot') syndrome. Incidence, recognition and management Am J Clin Dermatol. 2000;1(4):225-34. doi: http://dx.doi. org/10.2165/00128071-200001040-00004

7. Zuehlke RL. Erythematous eruption of the palms and soles associated with mitotane therapy. Dermatologica. 1974;148(2):90-2. doi: http://dx.doi. org/10.1159/000251603

8. Department of Health and Human Services (U.S.), National Institutes of Health, National Cancer Institute. Common Terminology Criteria for Adverse Events (CTCAE) [Internet]. Version 5.0. [Bethesda, Md.]: U.S. Dept. of Health and Human Services, National Institutes of Health, National Cancer Institute; 2017 Nov 27. [cited 2018 Dec 3]. Available from: https://ctep.cancer. gov/protocolDevelopment/electronic_applications/docs/ CTCAE_v5_Quick_Reference_8.5x11.pdf

9. Macedo LT, Lima JP, Santos LV, et al. Prevention strategies for chemotherapy-induced hand-foot syndrome: a systematic review and meta-analysis of prospective randomised trials. Support Care Cancer. 2014;22(6):1585-93. doi: http://dx.doi.org/10.1007/ s00520-014-2129-z

10. Avancini J, Zucchi P. Prevalence of dermatoses in patients referred for evaluation in an outpatient clinic of specialties. An Bras Dermatol. 2018;93(4):513-6. doi: http://dx.doi.org/10.1590/abd1806-4841.20186640

11. Moher D, Liberati A, Tetzlaff J, et al. Preferred reporting items for systematic reviews and meta-analyses: the PRISMA statement. J Clin Epidemiol. 2009. 62(10):100612. doi: http://dx.doi.org/10.1016/j.jclinepi.2009.06.005

12. Cochrane Effective Practice and Organisation of Care (EPOC). EPOC resources for review authors [Internet]. Oxford: Cochrane; 2017. [cited 2017 July 12]. Available from: http://epoc. cochrane.org/epoc-specific-resourcesreview-authors

13. McCarthy AL, Shaban RZ, Gillespie K, et al. Cryotherapy for docetaxel-induced hand and nail toxicity: randomised control trial. Support Care Cancer. 2014;22(5):1375-83. doi: http://dx.doi.org/10.1007/s00520-013-2095-x 
14. Scotté F, Tourani JM, Banu E, et al. Multicenter study of a frozen glove to prevent docetaxel-induced onycholysis and cutaneous toxicity of the hand. J Clin Oncol. 2005; 23(19): 4424-9. doi: http://dx.doi.org/10.1200/ JCO.2005.15.651

15. von Gruenigen V, Frasure H, Fusco N, et al. A doubleblind, randomized trial of pyridoxine versus placebo for the prevention of pegylated liposomal doxorubicinrelated hand-foot syndrome in gynecologic oncology patients. Cancer. 2010;116(20):4735-43. doi: http:// dx.doi.org/10.1002/cncr.25262

16. Zhao C, Chen J, Yu B, et al. Effect of modified Taohongsiwu decoction on patients with chemotherapyinduced hand-foot syndrome. J Tradit Chin Med. 2014;34(1):10-4. doi: https://doi.org/10.1016/S02546272(14)60047-9

17. Hofheinz RD, Gencer D, Schulz H, et al. Mapisal versus urea cream as prophylaxis for capecitabine associated hand-foot syndrome: a randomized phase III trial of the AIO Quality of Life Working Group. J Clin Oncol. 2015;33(22):2444-9. doi: https://doi.org/10.1200/ JCO.2014.60.4587

18. Ren Z, Zhu K, Kang H, et al. Randomized controlled trial of the prophylactic effect of urea-based cream on the hand-foot skin reaction associated with sorafenib in advanced hepatocellular carcinoma. J Clin Oncol. 2015;33(8):894-900. doi: https://doi.org/10.1200/ JCO.2013.52.9651

19. Yoshimoto N, Yamashita T, Fujita T, et al. Impact of prophylactic pyridoxine on occurrence of handfoot syndrome in patients receiving capecitabine for advanced or metastatic breast cancer. Breast Cancer. 2010;17(4):298-302. doi: https://doi.org/10.1007/ s12282-009-0171-3

20. Kawaguchi K, Ishiguro H, Morita S, et al. Correlation between docetaxel-induced skin toxicity and the use of steroids and $\mathrm{H}_{2}$ blockers: a multi-institution survey. Breast Cancer Res Treat. 2011;130(2):627-34. doi: https://doi.org/10.1007/s10549-011-1641-9

21. Dalenc F, Ribet V, Rossi AB, et al. Efficacy of a global supportive skin care programme with hydrotherapy after non-metastatic breast cancer treatment: a randomised, controlled study. Eur J. Cancer Care. 2018;27(1):e12735. doi: https://doi.org/10.1111/ecc.12735

22. Bardia A, Loprinzi CL, Goetz MP. Hand-foot syndrome after dose-dense adjuvant chemotherapy for breast cancer: a case series. J Clin Oncol. 2006;24(13):e18-9. doi: https://doi.org/10.1200/JCO.2006.06.1143

23. Farhat MH, El-Saghir NS, Shamseddine Al. Hand-foot syndrome with docetaxel: a five-case series. Ann Saudi Med. 2008;28(5):374-7. Ann Saudi Med. 2008 SepOct;28(5):374-377. doi: https://doi.org/10.5144/02564947.2008.374
24. Kara IO, Sahin B, Erkisi M. Palmar-plantar erythrodysesthesia due to docetaxel-capecitabine therapy is treated with vitamin $\mathrm{E}$ without dose reduction. Breast. 2006;15(3):414-24. doi: https://doi.org/10.1016/j. breast.2005.07.007

25. Chew L, Chuen VS. Cutaneous reaction associated with weekly docetaxel administration. J Oncol Pharm Pract. 2009;15(1):29-34. doi: https://doi.org/10.1016/10.117 7/1078155208096111

26. Wang JZ, Cowley A, McLellan BN. Differentiating hand-foot syndrome from tinea in patients receiving chemotherapy. Acta Oncol. 2016;55(8):1061-4. doi: https://doi.org/10.3109/0284186X.2016.1155739

27. Corazza M, Minghetti S, Borghi A, et al. Hand-foot syndrome caused by docetaxel with no recurrence after switch to paclitaxel, a different taxane. Int J Dermatol. 2014;53(3):e180-2. doi: https://doi.org/10.1111/j.13654632.2012.05782.x

28. Richards KN, Ivan D, Rashid RM, et al. Paclitaxel-induced acral erythema. Arch Dermatol. 2012;148(11):1333-4. doi: https://doi.org/10.1001/archdermatol.2012.2830

29. Housholder AL, Adams BB. Chemotherapy-induced acral erythema sparing the palms. J Am Acad Dermatol. 2012;67(3):e116-7. doi: https://doi.org/10.1016/j. jaad.2011.09.031

30. Ozkol HU, Calka O, Bulut G. Chemotherapy-induced acral erythema with involvement of the face and neck: a case report. Toxicol Ind Health. 2016;32(5)791-4. doi: https://doi.org/10.1177/0748233713511514

31. Sauter C, Saborowski A, Ockenfels HM. Unilaterale akrale nekrosen als abortivform einer palmoplantaren erythrodysästhesie. Hautarzt. 2007;58(7):619-22. doi: https://doi.org/10.1007/s00105-006-1227-3

32. Akoglu G. Docetaxel-induced palmoplantar erythrodysesthesia syndrome and long-lasting multiple nail changes. Indian J Pharmacol. 2014;46(2):225-7. doi: https://doi.org/10.4103/0253-7613.129326

33. Braghiroli CS, Ieiri R, Ocanha JP, et al. Do you know this syndrome? Hand-foot syndrome. An Bras Dermatol. 2017;92(1):131-133. doi: http://dx.doi.org/10.1590/ abd1806-4841.20174602

34. Jung S, Sehouli J, Patzelt A, et al. Influence of mechanical stress on palmoplantar erythrodysesthesia - a case report. Oncol Res Treat. 2015;38(1-2):42-4. doi: http://dx.doi. org/10.1159/000370343

35. Qiao J, Fang H. Hand-foot syndrome related to chemotherapy. CMAJ. 2012;184(15):E818. doi: http:// dx.doi.org/10.1503/cmaj.111309

36. Katoh M, Kadota M, Nishimura Y. A case of docetaxelinduced erythrodysesthesia. J Dermatol. 2004;31:4036. doi: http://dx.doi.org/10.1111/j.1346-8138.2004. tb00692.x 
37. Gurumurthi R, Nimmagadda RBV, Mohan S. Docetaxel-induced hand and foot syndrome in a patient with metastatic breast carcinoma. Indian J Dermatol, 2013;58(5):380-2. doi: http://dx.doi.org/10.4103/00195154.117309

38. Hoesly FJ, Baker SG, Gunawardane ND, et al. Capecitabine-induced hand-foot syndrome complicated by pseudomonal superinfection resulting in bacterial sepsis and death: case report and review of the literature. Arch Dermatol. 2011;147(12):1418-23. doi: http:// dx.doi.org/10.1001/archdermatol.2011.320

39. Jain A, Dubashi B. Docetaxel-induced hand foot syndrome: "No dose is a safe dose". J Pharmacol Pharmacother. 2012;3(2):200-201. doi: http://dx.doi. org/10.4103/0976-500X.95534

40. Assi HA, Ayoub ZA, Jaber SM, et al. Management of Paclitaxel-induced hand-foot syndrome. Breast Care (Basel). 2013;8(3):215-7. doi: http://dx.doi. org/10.1159/000352097

41. Simão DAS, Lima EDRP, Souza RS, et al. Síndrome mão-pé induzida por quimioterapia: relato de um caso. Rev Bras Enferm. 2012; 65(2): 374-8. doi: http://dx.doi. org/10.1590/S0034-71672012000200026

42. Guyatt G, Oxman AD, Akl EA, et al. GRADE guidelines: 1. Introduction-GRADE evidence profiles and summary of findings tables. J Clin Epidemiol. 2011;64(4):383-94. doi: http://dx.doi.org/10.1016/j.jclinepi.2010.04.026

43. Viera AJ, Garrett JM. Understanding interobserver agreement: the kappa statistic. Fam Med [Internet]. 2005 May [cited 2018 Dec 3];37(5):3603. Available from: https://fammedarchives. blob.core.windows.net/imagesandpdfs/pdfs/ FamilyMedicineVol37Issue5Viera360.pdf

44. Watkins AA, Johnson TV, Shrewsberry AB, et al. Ice packs reduce postoperative midline incision pain and narcotic use: a randomized controlled trial. J Am Coll Surg. 2014;219(3):511-7. doi: http://dx.doi. org/10.1016/j.jamcollsurg.2014.03.057

45. Danby SG, Brown K, Higgs-Bayliss T, et al. The effect of an emollient containing urea, ceramide NP, and lactate on skin barrier structure and function in older people with dry skin. Pharmacol Physiol 2016;29:135-147. doi: https://doi.org/10.1159/000445955

46. Wannmacher L. Medicamentos de uso corrente no manejo de dor e febre. Brasília, DF: Ministério da Saúde; 2012.

47. Janusch M, Fischer M, Marsch HAB, et al. The handfoot syndrome--a frequent secondary manifestation in antineoplastic chemotherapy. Eur J Dermatol. 2006;16(5):494-9. doi: http://dx.doi.org/10.1684/ ejd.2006.0041

48. Addor FAS, Aoki V. Barreira cutânea na dermatite atópica. An Bras Dermatol. 2010;85(2):184-94. doi: http://dx.doi.org/10.1590/S0365-05962010000200009
49. Richardson J, Smith JE, McIntyre M, et al. Aloe vera for preventing radiation-induced skin reactions: a systematic literature review. Clin Oncol (R Coll Radiol). 2005;17(6):478-84. doi: https://doi.org/10.1016/j. clon.2005.04.013

50. Hekmatpou D, Mehrabi F, Rahzani K, et al. The effect of aloe vera clinical trials on prevention and healing of skin wound: a systematic review. Iran J Med Sci. 2019;44(1):1-9. doi: https://doi.org/10.30476/ IJMS.2019.40612

51. Chan A, Cameron MC, Garden B, et al. A systematic review of patient-reported outcome instruments of dermatologic adverse events associated with targeted cancer therapies. Support Care Cancer. 2015;23(8):223144. doi: http://dx.doi.org/10.1007/s00520-014-2564-x

Recebido em 25/7/2019 Aprovado em 7/11/2019 